\title{
Risk factors in prolonged postpartum urinary retention: an analysis of six cases
}

\author{
Joerg Humburg • Carolyn Troeger • \\ Wolfgang Holzgreve $\cdot$ Irene Hoesli
}

Received: 10 June 2009 / Accepted: 1 December 2009 / Published online: 19 December 2009

(C) Springer-Verlag 2009

\begin{abstract}
Purpose Prolonged first and second stage of labor, isolated prolongation of the second stage, forceps delivery or vacuum extraction, perineal laceration, nulliparity and epidural anesthesia are known risk factors for developing prolonged postpartum urinary retention (PUR). The aim of our study was to analyze number and constellations of these risk factors, in prolonged postpartum urinary retention (PPUR) in our own unit to facilitate the identification of patients at high risk and thus to prevent bladder overdistension by early intervention.

Methods We performed a retrospective analysis of all our cases with PPUR between 2003 and 2008 including variables like age weight, height, body mass index, fetal birth weight and head circumference.

Results The incidence of PPUR at our institution is low being $0.06 \%$. No woman combined all six risk factors. The majority had five risk factors, all had at least four. An isolated prolonged second stage of labor was common to all patients with PPUR. Five women had an epidural anesthesia, three were nulliparous and only two women delivered spontaneously. All but one woman suffered from perineal tears. Interestingly, fetal head circumference was larger than $36 \mathrm{~cm}$ in four of six cases.

Conclusion In contrast to simple PUR, the prolonged form of PUR could be the result of a cumulative effect of different single risk factors.
\end{abstract}

J. Humburg $(\bowtie) \cdot$ C. Troeger $\cdot$ I. Hoesli

Department of Obstetrics and Gynecology,

University Women's Hospital, Spitalstrasse 21,

4031 Basel, Switzerland

e-mail: jhumburg@uhbs.ch

W. Holzgreve

University Medical Center University of Freiburg,

Hugstetter Str. 49, 79106 Freiburg, Germany
Keywords Postpartum urinary retention - Episiotomy · Perineal laceration $\cdot$ Vaginal delivery $\cdot$ Fetal head circumference $\cdot$ Prolonged second stage of labor

\section{Introduction}

The prevalence of postpartum urinary retention (PUR) is low, but the reported frequencies vary in recent publications from 0.05 to $14.1 \%$ depending on the definitions used [1,2]. Although PUR may be a transient phenomenon it is well known that even a single episode of bladder distention can irreversibly damage the detrusor muscle, therefore resulting in permanent voiding dysfunction [2-4]. However, because a proper definition is missing it is difficult to compare the findings of different clinical trials and to establish clinical guidelines for prevention, screening and treatment. If the most sensitive factors predisposing for PUR could be identified during or shortly after delivery, women at risk could easily be identified and bladder distention could be omitted through effective and early treatment (e.g., catheterization) without bothering the majority of women with a very aggressive approach as is proposed in some studies [5].

Several risk factors for the development of PUR are mentioned in the literature. Using uni- and multivariate regression analyses several authors describe mostly identical risk factors, but also different independent risk factors, such as prolonged first and second stage of labor, isolated prolongation of the second stage, forceps delivery or vacuum extraction, perineal laceration, and nulliparity [3, 5-8]. Epidural anesthesia as a risk factor is controversially discussed; its use may at least increase the risk of PUR [2, 4, 5, 7].

All the above-mentioned factors are quite common in daily obstetrical practice. They also often depend on and 
may even promote each other. However, in a time of limited resources it seems to be impractical to screen all patients. These efforts should be concentrated on identified high risk patients. Additionally, a less aggressive approach would lower the number of unnecessary, costly and bothersome interventions.

From our clinical practice we hypothesized that a certain number and constellation of risk factors during delivery predispose patients to develop prolonged PUR (PPUR). We therefore analyzed the appearance and combination of the known risk factors in our PPUR patients.

\section{Materials and methods}

In accordance to the current literature PUR is at our institution defined as the lack of spontaneous micturition more than $6 \mathrm{~h}$ after any vaginal delivery. If this disturbance lasts at least 7 days, or a postvoid residual bladder volume (PVRBV) is $>150 \mathrm{ml}$ patients suffer from PPUR. The period of 7 days was chosen, after the findings of one large study, in which PUR resolved spontaneously after 5 days in all cases, therefore surpassing this limit indicates a nonresolving situation [3]. In another study, persistent urinary retention was defined as the inability to void after an even shorter period of time, i.e., 3 days treatment with an indwelling catheter [1]. The volume of $150 \mathrm{ml}$ was chosen as the normal upper limit according to the first study mentioned, in which all cases with less than this volume spontaneously resolved [3].

We performed a retrospective study on patients diagnosed with PPUR based on the above criteria between January 2003 and January 2008. From their medical records we gained information regarding the known risk factors, e.g. prolonged first and second stage of labor exceeding $10 \mathrm{~h}$, isolated prolongation of the second stage exceeding $60 \mathrm{~min}$, forceps delivery or vacuum extraction, perineal laceration classified as perineal tears grade II and III, vaginal tears and mediolateral episiotomy, nulliparity, and the use of an epidural anesthesia [3, 5-8].

Common maternal characteristics like age, weight, height and body mass index (BMI), as well as fetal characteristics, like birth weight and fetal head circumference were also collected and analyzed and compared with data extracted from clinical case studies dealing with PUR.

\section{Results}

During the study period of 5 years, a total of 9,295 women delivered vaginally at our institution. Amongst them we identified six women who developed PPUR (incidence of $0.06 \%)$.
Table 1 Maternal and fetal characteristics

\begin{tabular}{lc}
\hline & Women with PPUR \\
& Mean \pm SD \\
\hline Age (years) & $31.8 \pm 6.1$ \\
Weight $(\mathrm{kg})$ & $80.3 \pm 7.8$ \\
Height $(\mathrm{cm})$ & $166.3 \pm 5.7$ \\
Body mass index (BMI) & $29.7 \pm 3.85$ \\
Birth weight (g) & $3,834.2 \pm 354.6$ \\
Fetal head circumference $(\mathrm{cm})$ & $36.2 \pm 1.17$ \\
\hline
\end{tabular}

All our patients with PPUR had a PVRBV $>150 \mathrm{ml}$ 7 days after delivery. In all of them PPUR resolved within weeks, with the longest period of PPUR lasting 8 weeks.

Maternal and fetal characteristics are listed in Table 1. Mean age (years) was $31.8 \pm 6.1$, mean weight $(\mathrm{kg})$ was $80.3 \pm 7.8$, mean height $(\mathrm{cm}) 166.3 \pm 5.7$, mean BMI $29.7 \pm 3.85$, mean birth weight $(\mathrm{g})$ was $3,834.2 \pm 354.6$ and mean fetal head circumference $36.2 \pm 1.17$. Three of six had a BMI $>30$, two $>25$, only one $>20$. No newborn was more than $4,500 \mathrm{~g}$, only one was $>4,000 \mathrm{~g}$. Fetal head circumference was in four out of six $37 \mathrm{~cm}$.

No woman had a combination of all six known risk factors, but the majority of PPUR patients $(n=4)$ had at least five out of six risk factors. A long first and second stage of labor that exceeded $10 \mathrm{~h}$ was present in five women. A prolonged second stage of labor ( $>1 \mathrm{~h}$ ) was seen in all women. Only two women delivered spontaneously, whereas four had a vacuum extraction. Half of the patients were nulliparous. An epidural anesthesia was applied in five cases. Looking at the perineal laceration in detail revealed that five out of six patients had any type of perineal trauma. Only one woman delivered with intact perineum, four with perineal tears, two with II and two with III degree. One had a combination of a mediolateral episiotomy and a vaginal tear. No patient had signs of an anterior trauma, i.e., periurethral or clitoral laceration. Table 2 summarizes the risk factors in our patients.

\section{Discussion}

Our study shows that majority of women with PPUR had an accumulation of five risk factors. PPUR is a rare clinical entity which is much like PUR, lacking a clear and concise definition. Up to now only studies with small patient cohorts or case reports have been published [1,9-11]. Only one study discusses clearly the problem of persistent or PPUR. The prevalence of $0.05 \%$ in that study corresponds to our finding of $0.06 \%$ [1]. In other studies no difference between PUR and PPUR is made. Thus these studies are 
Table 2 Risk factors in the PPUR cases

\begin{tabular}{|c|c|c|c|c|c|c|c|}
\hline \multirow[t]{2}{*}{ PUR case no. } & \multicolumn{6}{|l|}{ Risk factors } & \multirow{2}{*}{$\begin{array}{l}\text { Sum of risk } \\
\text { factors }\end{array}$} \\
\hline & $\begin{array}{l}\text { First/second } \\
\text { stage }>10 \mathrm{~h}\end{array}$ & $\begin{array}{l}\text { Second } \\
\text { stage }>1 \mathrm{~h}\end{array}$ & Delivery & Perineal tear & Nulliparity & $\begin{array}{l}\text { Epidural } \\
\text { anesth. }\end{array}$ & \\
\hline 1 & + & + & Spontan. & None & + & + & 4 \\
\hline 2 & + & + & Spontan. & $\mathrm{II}^{\circ}$ tear & - & + & 4 \\
\hline 3 & + & + & Vacuum & $\mathrm{III}^{\circ}$ tear & + & - & 5 \\
\hline 4 & + & + & Vacuum & III $^{\circ}$ tear & - & + & 5 \\
\hline 5 & + & + & Vacuum & $\mathrm{II}^{\circ}$ tear & - & + & 5 \\
\hline 6 & - & + & Vacuum & Episiotomy, Vaginal tear & + & + & 5 \\
\hline$\sum(+)$ & $5 / 6$ & $6 / 6$ & $4 / 6$ & $4 / 6$ & $3 / 6$ & $5 / 6$ & \\
\hline
\end{tabular}

not suitable for comparison [6, 8]. Risk factors described for PPUR involve vaginal delivery after cesarean section, prolonged second stage of labor, epidural anesthesia, forceps delivery, nulliparity, and delayed diagnosis and intervention [1, 9-11].

In contrast to PUR, the clinical course of PPUR is longer and implies a longer need for catheterization, which indicates that the damage to the bladder is more severe. One study showed that PUR patients with a PVRBV $<750 \mathrm{ml}$ required a significantly shorter duration of bladder catheterization, compared to those with PVRBV $>750 \mathrm{ml}$, namely 17 versus 27 days [5]. In the publications on PPUR, PVRBV ranged from 600 to 2,000 $\mathrm{ml}$ [1,9-11]. Our series with PVRBV varies from 600 to $3,400 \mathrm{ml}$ supporting this observation.

Maternal characteristics as listed in Table 1 are difficult to compare with the data published in the literature because very often they are not completely mentioned in the studies. The maternal age varies between 25 and 28 years, the mean age of our patients is within these limits [5, 12]. Surprisingly there are scarce the data on BMI and PUR. We found only two studies using the BMI to characterize the study population with PUR. There the mean BMI was $23 \pm 4.0$, respectively, 28. Our patients have an average BMI of is $29.7 \pm 3.8$, being categorized as overweight [8, 13]. Generally there is a known, clear association between maternal overweight and adverse obstetrical and perinatal outcome, with an increased incidence of pre-eclampsia, gestational diabetes, hypertension, macrosomia, induction of labor and cesarean section [14]. None of these obstetrical complications was present in our patients.

Many studies have shown that fetal birth weight has no impact on the development of PUR [3, 5, 8, 15]. Fetal head circumference was considered as a possible risk factor only in three studies, but was found not statistically significant in two of them $[6,16]$. Only one german study demonstrated that a newborn head circumference of $>36 \mathrm{~cm}$ is a significant risk factor for PUR [17]. Four of our six patients had fetal head circumference of $37 \mathrm{~cm}$. Due to missing data in the current PUR literature, we can not draw any conclusion from our observation.

There is evidence in the current literature, that an increased fetal head circumference has the potential to damage at least the posterior compartment of the pelvic floor. Recent studies have demonstrated that a larger fetal head circumference is associated with more perineal damage, mostly anal sphincter tears [18, 19].

Yet none of the PUR studies has focused attention on the type of perineal damage and its possible effect on the anterior compartment.

A relationship between perineal damage and PUR has been reported by many researchers [1, 3, 7, 8, 20]. Musselwhite et al. [7] showed in their retrospective cohort study that women with PUR had a high incidence of second and third degree tears, but also mediolateral episiotomy was a very common procedure. After applying logistic regression analysis to the different kinds of perineal damage only perineal laceration remained statistically significant. This finding suggests that there is a difference in the impact of perineal tears and episiotomies on the development of PUR, but these two different types of perineal damage were never directly compared in regard to PUR. In another PUR study [6] a mediolateral episiotomy was performed in all women. The number of additional perineal lacerations was statistically significant between the PUR and the control group. The severity of perineal lacerations, anal sphincter muscle tears or first and second degree tears had no effect on the incidence of PUR [21]. In contrast to our findings and those of others [6, 7], Yip et al. [3] found no differences in the incidence of birth canal trauma between patients with covert urinary retention with overt urinary retention and without PUR. The absence of PPUR in their study could be interpreted as the results of the high rate of episiotomies of about $89 \%$, and therefore their experiences would be in line with our results.

Some authors [5, 8] do not mention perineal lacerations in their studies at all, which makes it very difficult to 
compare the impact of the perineal damage to PPUR. As with other rare obstetrical events, collecting the data from more than one center would facilitate obtaining reliable estimates [5].

It is difficult to compare the cases available in the literature with our group of patients, since the heterogeneity originating from different countries with probably different obstetrical practices [1, 9-11].

Furthermore because of the lack of detailed information on all six known risk factors, it is not possible to compare these cases of PPUR with ours. Ten cases are presented in these studies, in only six cases the authors refer to perineal damage, and one delivered by cesarean section $[1,10,11]$. The duration of first and second stages of labor is not well differentiated, so isolated prolongation of the second stage cannot be assessed. In contrast to our findings the rate of episiotomies is remarkably high, even in cases of spontaneous vaginal delivery. This brings us to the assumption that this contradictory finding is due to routinely applied episiotomies in daily obstetrical practice, notably where forceps extractions were done. Therefore, the use of episiotomy in these cases does not rule out its possible protective effect in PPUR.

In PUR, episiotomy is described as a risk factor only when a univariate analysis was made [1, 3, 8]. In current obstetrical practice, restrictive episiotomy policies are widely used because of a higher number of benefits when compared to the formerly routine use of prophylactic episiotomy. Restrictive use is associated with less posterior perineal trauma, less suturing, and fewer healing, i.e. pain related problems. It is known, however, that omitting episiotomy leads to an increased risk of anterior trauma, such as periurethral lacerations [21]. Restrictive policy is not associated with increased vaginal or perineal trauma, dyspareunia, urinary incontinence or several pain measures. Since there is no increased need for suturing anterior lacerations, it might be concluded that these anterior lesions are less severe [22].

In the most current literature on the value of restrictive episiotomy policies as reviewed by Carroli and Belizan, PUR and anterior trauma were not yet an issue; the main interest was focused on the perineum, i.e. pain, dyspareunia and most importantly third degree tears. Only little information is given regarding the anterior trauma in terms of urinary incontinence or spontaneous resolution of PUR [22]. Based on our data, however, one could speculate on a possible negative side effect of this restrictive episiotomy policy on the anterior compartment in a well-defined subgroup of women.

The pathophysiology of PPUR is poorly understood. Various mechanisms have been discussed, such as bladder neck obstruction due to tissue edema [2]. This damage to muscle and nervous tissue, might develop as a consequence of the direct compression from the fetal presenting part and the downward pressure from maternal expulsive efforts [15]. In accordance to the literature our cases show that a fetal head circumference of $37 \mathrm{~cm}$ is significantly associated with a prolonged first and second stage of labor [23]. Consequently levator muscle injuries in the posterior compartment might develop [19]. For the anterior compartment, however, there is a weak statistical association reported between fetal head circumference and urinary incontinence [24].

Known clinical consequences of prolonged second stage of labor are an increased maternal morbidity, in multivariate analyses excluding confounding factors like episiotomy, this due to postpartum hemorrhage, infection, perineal laceration and operative delivery are [25].

It is interesting to note that in an extensively done systematic review, which analyzed adverse maternal and fetal outcome after prolonged second stage of labor only study could be identified who looked a voiding dysfunction, illustrating the paucity of data in this field of obstetrics and urogynecology [26].

Our study has two main limitations: first of all, the small number of patients and second its retrospective design. However, even with a case number of six patients, this is, to the best of our knowledge the largest published study PPUR. Due to is nature and low incidence we hypothesize that it be difficult in the future to perform a prospective randomized study on PPUR patients to test which intervention would improve outcome.

From our small, but well characterized study population, we hypothesize that an additive effect of different risk factors is responsible that not a simple, but a PPUR develops.

In our opinion PPUR is-though rare-relevant since a single episode of bladder overdistension can lead to severe bladder dysfunction due to irreversible damage to the detrusor muscle [4].

From our point of view and experience in caring for our patients with PPUR, this is a severe issue especially because it concerns healthy young women and not much is known (or has been published) about long-term sequelae [2]. We would therefore propose to increase the body of knowledge by extensive data recording as done in other rare obstetrical events [27].

Conflict of interest statement We declare that we have no conflict of interest.

\section{References}

1. Groutz A, Gordon D, Wolman I, Jaffa A, Kupferminc MJ, Lessing B (2001) Persistent postpartum urinary retention in contemporary obstetric practice. J Reprod Med 46:44-48

2. Yip SK, Sahota D, Pang MW, Chang A (2004) Postpartum urinary retention. Acta Obstet Gynecol Scand 83:881-891 
3. Yip SK, Briger G, Hin LY, Chung T (1997) Urinary retention in the postpartum period. The relationship between obstetric factors and the post-partum post-void residual bladder volume. Acta Obstet Gynecol Scand 76:667-672

4. Mayo ME, Lloyd-Davies RW, Shuttleworth KED, Tighe JR (1973) The damaged human detrusor: functional and electron microscopic changes in disease. BJU 45:116-125

5. Teo R, Punter J, Abrams K, Mayne C, Tincello D (2007) Clinically overt postpartum urinary retention after vaginal delivery: a retrospective case-control study. Int Urogynecol J Pelvic Floor Dysfunct 18:521-524

6. Liang CC, Chang SD, Tseng LH, Hsieh CC, Chung CL, Cheng PJ (2002) Postpartum urinary retention: assessment of contributing factors and long-term clinical impact. Aust N Z J Obstet Gynaecol 4:367-370

7. Musselwhite KL, Faris P, Moore K, Berci D, King KM (2007) Use of epidural anesthesia and the risk of acute postpartum urinary retention. Am J Obstet Gynecol 196:472.e1-472.e5

8. Carley ME, Carley JM, Vasdev G, Lesnick TG, Webb MJ, Ramin KD et al (2002) Factors that are associated with clinically overt postpartum urinary retention after vaginal delivery. Am J Obstet Gynecol 187:430-433

9. Jeffery TJ, Thyer B, Tsokos N, Taylor JD (1990) Chronic urinary retention postpartum. Aust N Z J Obstet Gynaecol 4:364-366

10. Watson WJ (1991) Prolonged postpartum urinary retention. Mil Med 9:502-503

11. Kulkarni R, Bradford WP, Foster SJ, James ED (1994) Chronic retention of urine following childbirth-a rare complication in the puerperium. Aust N Z J Obstet Gynaecol 1:107-108

12. Kermans G, Wyndaele JJ, Thiery M, De Sy W (1986) Puerperal urinary retention. Acta Urol Belg 54:376-385

13. Rizvi RM, Khan ZS, Khan Z (2005) Diagnosis and management of postpartum urinary retention. Int J Gynaecol Obstet 91:71-72

14. Bhattacharya S, Campbell DM, Liston WA, Bhattacharya S (2007) Effect of body mass index on pregnancy outcomes in nulliparous women delivering singleton babies. BMC Public Health 24(7):168

15. Yip SK, Sahota D, Pang MW, Chang A (2005) Screening test model using duration of labor for the detection of postpartum urinary retention. Neurourol Urodyn 24:248-253
16. Demaria F, Amar N, Biau D, Fritel X, Porcher R, Amarenco G et al (2004) Prospective 3D ultrasonographic evaluation of immediate postpartum urine retention volume in 100 women who delivered vaginally. Int Urogynecol J 15:281-285

17. Wenderlein JM, Revermann S (1994) Harnblasenentleerungsstörungen nach der Geburt. Z Geburtshilfe Perinatol 198:47-51

18. Fitzgerald MP, Weber AM, Howden N, Cundiff GW, Brown MB (2007) Pelvic floor disorders network. Risk factors for anal sphincter tear during vaginal delivery. Obstet Gynecol 109:29-34

19. Valsky DV, Lipschuetz M, Bord A, Eldar I, Messing B, HochnerCelnikier D et al (2009) Fetal head circumference and length of second stage of labor are risk factors for levator ani muscle injury, diagnosed by 3-dimensional transperineal ultrasound in primiparous women. Am J Obstet Gynecol 201:91-97

20. Glavind K, Bjork J (2003) Incidence and treatment of urinary retention postpartum. Int Urogynecol J 14:119-121

21. Carroli G, Belizan J (1999) Episiotomy for vaginal birth. Cochrane Database Syst Rev (3):CD000081. doi:10.1002/14651858. CD000081

22. ACOG Practice Bulletin (2006) Episiotomy. Clinical Management Guidelines for Obstetrician-Gynecologists. Obstet Gynecol 107:957-962

23. Kennelly MM, Anjum R, Lyons S, Burke G (2003) Postpartum fetal head circumference and its influence on labour duration in nullipara. J Obstet Gynaecol 23:496-499

24. Wesnes SL, Hunskaar S, Bo K, Rortveit G (2009) The effect of urinary incontinence status during pregnancy and delivery mode on incontinence postpartum. A cohort study. BJOG 116:700-707

25. Cheng YW, Hopkins LM, Caughey AB (2004) How long is too long: does a prolonged second stage of labor in nulliparous women affect maternal and neonatal outcomes? Am J Obstet Gynecol 191:933-938

26. Altman MR, Lydon-Rochelle MT (2006) Prolonged second stage of labor and risk of adverse maternal and perinatal outcomes: a systematic review. Birth 33:315-322

27. Knight M, Kurinczuk JJ, Tuffnell D, Brocklehurst P (2005) The UK obstetric surveillance system for rare disorders of pregnancy. BJOG 112:263-265 